\title{
Statistical analysis of contents of posts on SNSs by foreign visitors to Japan based on questionnaire survey
}

Ayako Sawada (Hokuriku Gakuin Junior College, sawada@hokurikugakuin.ac.jp, Japan)

\begin{abstract}
The purpose of this study is to clarify the characteristics of the contents of posts on SNSs by foreign visitors to Japan regarding their trips and the difference in the contents of posts depending on the region from which they are from, age group, and gender. Targeting foreign visitors aged 15 years or older who visited Kanazawa City in Ishikawa prefecture and wrote posts on SNSs, a questionnaire survey was carried out. The questionnaire items related to the contents of posts are the same as the questionnaire survey by Japan Travel and Tourism Association for Japanese people who travelled to Japan and wrote posts on SNSs. Statistical analysis was performed using SPSS Statics 25 on the responses. The results indicate that the range of topics in posts by foreign visitors is more than double those in posts by Japanese tourists, that the contents of posts by foreign visitors can be classified into three groups, that the contents and the number of types of posts depend on the region where they are from, and that the number of posts on "member of a party" depend on gender. SNSS are considered to play an important role in determining the destination of travel. The results in this study provide important suggestions for tourism strategy planning using SNSS.
\end{abstract}

\section{Keywords}

foreign visitors to Japan, SNS, questionnaire survey, statistical analysis, correspondence analysis

\section{Introduction}

According to the 2018 White Paper on Information and Communications in Japan published by the Ministry of Internal Affairs and Communications, the percentages of people who actively transmit information or express their opinions on Facebook were $45.7 \%$ in the US, $34.9 \%$ in the UK, and $25.9 \%$ in Germany, which are much higher than that in Japan (5.5\%). According to the 2017 Foreign Visitors Consumption Trends Survey Report, the information sources that are most useful to foreign visitors before visiting Japan were blogs posted by individuals (31.2\%), SNSs (21.4\%), relatives and acquaintances in their country $(17.5 \%)$, and homepages organized by travel companies (16.6\%). Hu and Wei [2013] suggested that customers believe information that comes from personal sources rather than commercial sources. Fotis et al. [2011] demonstrated that there is a strong correlation between level of influence from SNSs and changes made to holiday plans. Tourists themselves have provided information through blogs and SNSs, which then stimulate the interest of potential tourists [Burgess et al., 2011; Icoz et al., 2018; Zivkovic et al., 2014]. Hu et al. [2014] found that Instagram photos can be roughly categorized into eight types based on their content: self-portraits, friends, activities, captioned photo, food, gadgets, fashion and pets. Japan Travel and Tourism Association [2017] reported the results of a questionnaire survey regarding the contents of posts on SNSs targeting Japanese domestic tourists. Although understanding the contents of posts by foreign visitors to Japan is important in developing a strategy to attract foreign visitors, there has been little research on content posted by foreign visitors to Japan.

The purpose of this study is to clarify the characteristics of the contents of posts by foreign visitors to Japan regarding their trips and the difference in the contents of posts depending on the region from which they are from, age group, and gender.

\section{Contents of posts by Japanese tourists}

According to the 2016 States and Trends of Tourism published by Japan Travel and Tourism Association, the percentage of Japanese tourists who wrote posts on SNSs was 29.0 $\%$ among all Japanese tourists who travel in Japan and stay at least one night at their destination. Figure 1 shows the results of the questionnaire that allows multiple answers from among options regarding the contents of posts, regardless of the type of posts, i.e., text, photos, and video images.

The percentages of posts on "food and dining" (31.7\%), "natural scenery" (24.2\%), and "famous tourist spots" (22.9\%) were high.

\section{Research methods}

Targeting foreign visitors aged 15 years or older who visited Kanazawa City in Ishikawa prefecture and wrote posts on SNSs, a questionnaire survey was carried out from July 2018 to January 2019. Thanks to the cooperation of two guesthouses, the questionnaire sheets were placed in the rooms of the guesthouses, where the visitors completed the sheets voluntarily, or they were asked to complete the sheets at the front desk. Responses were obtained from a total of 162 foreign visitors (87 males and 75 females).

The questionnaire items include age, gender, nationality, length of stay in Kanazawa City, the contents of their posts on SNSs (multiple answers allowed), and places or objects of interest other than famous tourist spots (free description). To compare with the results for Japanese tourists, options regarding the contents of posts are the same items as shown in Figure 1. SPSS Statistics 25 software was used for statistical process- 


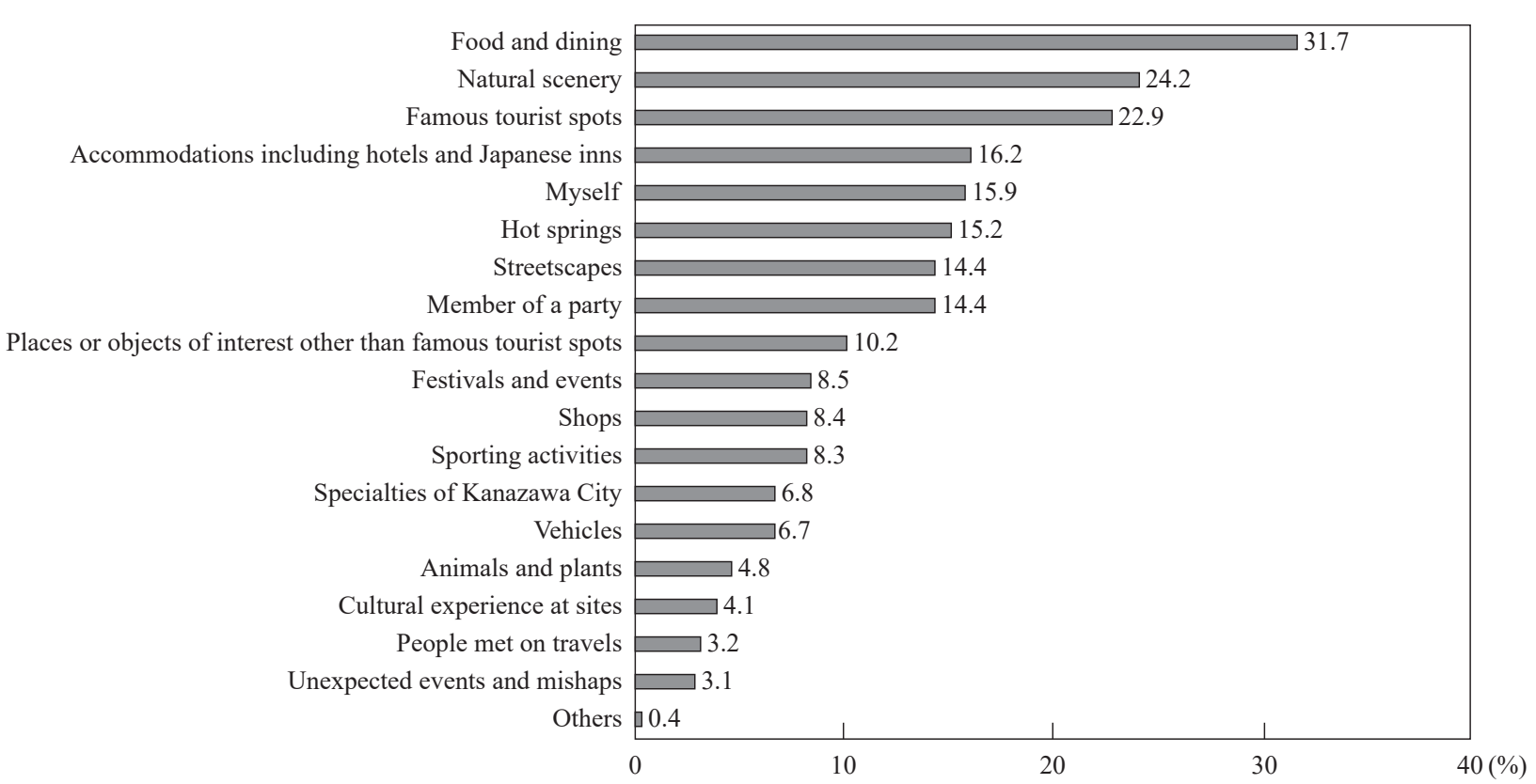

Figure 1: Percentage of posts on SNSs for each item by Japanese tourists during travel in Japan

ing.

\section{Results and discussions \\ 4.1 Number of nights}

According to the 2017 Survey Results Report on Kanazawa City Tourism by Kanazawa City, the number of nights stayed by Japanese tourists in Kanazawa was 0 (16.1\%), 1 (60.2\%), $2(21.2 \%), 3(2.1 \%)$, and 4 or more $(0.4 \%)$. The number of nights stayed by foreign visitors in this study was 1 (23.5\%), 2 (49.4\%), 3 (21.0\%), and 4 or more (6.2\%). All visitors stayed at least one night because the questionnaire was distributed to people staying in guesthouses. Foreign visitors tend to stay for more nights than Japanese tourists, although this might be explained by the fact that the information on Japanese tourists collected by Kanazawa City was obtained at JR Kanazawa train station and famous tourist spots.

\subsection{Contents of posts on SNSs by foreign visitors to Japan}

Figure 2 shows the results for the question allowing multiple answers regarding the contents of SNS posts on travel, regardless of the type of post, i.e., text, photos, and video images. The top three items selected by foreign visitors were the same as those selected by Japanese tourists, although their orders were different. The percentages of posts on "famous tourist spots", "food and dining", and "natural scenery" exceeded $50 \%$. The sum of the percentages of posts on all 19 items for foreign visi-

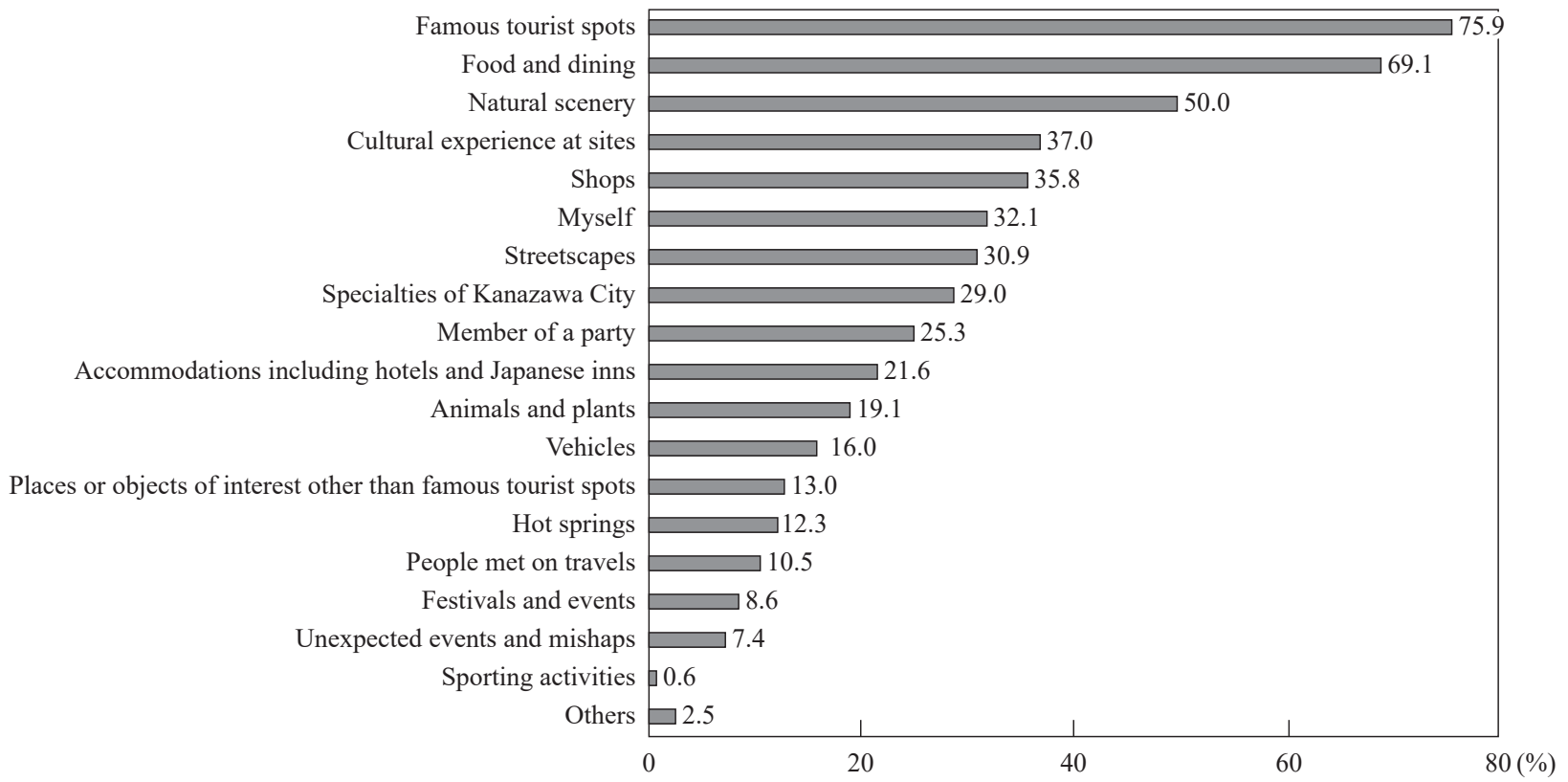

Figure 2: Percentage of posts on SNSs for each item by foreign visitors during travel in Japan 
tors was $496.7 \%$, whereas the sum of the percentages of posts for Japanese tourists was $219.4 \%$. This result indicates that the contents of posts by foreign visitors were wider ranging than those by Japanese tourists, suggesting that foreign visitors have greater potential to publicize tourist attractions in Japan than Japanese visitors.

\subsection{Classification of contents of posts}

Correspondence analysis is a method of expressing information summarized in rows and columns in cross-tabulation tables in two-dimensional, three-dimensional, or higher-dimensional figures. Correspondence analysis can also be applied to the analysis of responses obtained through a questionnaire that allows multiple answers and to classify options and respondents [Uchida, 2006].

Correspondence analysis was carried out to determine which items were simultaneously selected from among 18 items (excluding "others") regarding the contents of posts. Figure 3 shows the results of the classification. Some items were clustered together and these items were classified into three groups. Group 1 includes (4) "famous tourist spots", (7) "streetscapes", and (9) "natural scenery", which are "visual attractions". The average percentage of posts concerning the items in group 1 was $36.9 \%$. Group 2 includes (1) "food and dining", (3) "accommodations including hotels and Japanese inns", and (14) "cultural experience at sites", which are "tourist experiences during their trip", are included. The average percentage of posts for the items in group 2 was $29.0 \%$. In group 3, (16) “my-

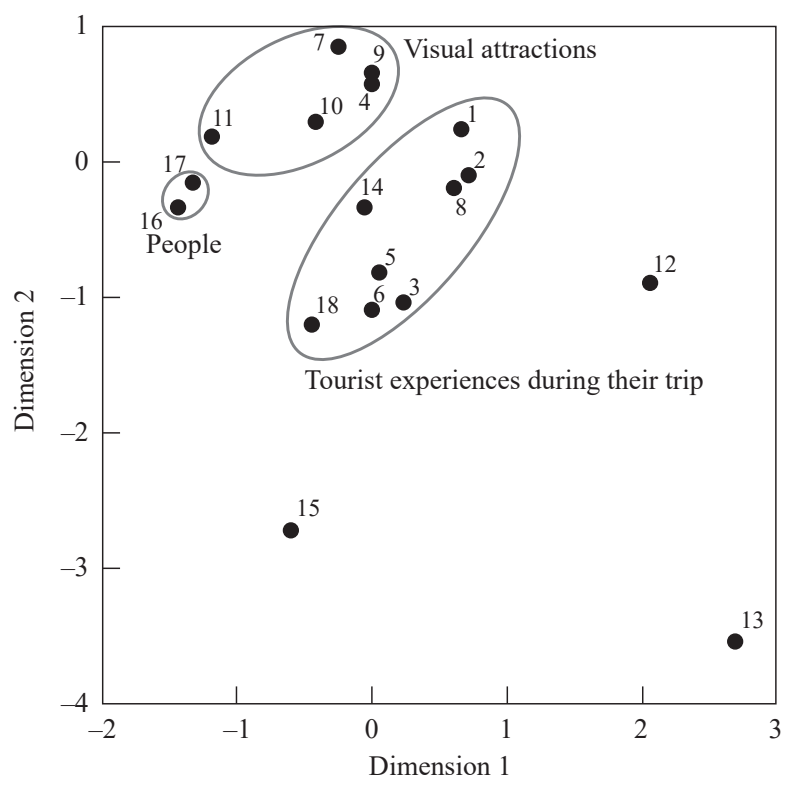

Figure 3: Classification of contents of posts

Notes: (1) Food and dining; (2) Shops; (3) Accommodations including hotels and Japanese inns; (4) Famous tourist spots; (5) Places or objects of interest other than famous tourist spots; (6) Vehicles; (7) Streetscapes; (8) Specialties of Kanazawa City; (9) Natural scenery; (10) Animals and plants; (11) Festivals and events; (12) Hot springs; (13) Sporting activities; (14) Cultural experience at sites; (15) Unexpected events and mishaps; (16) Myself; (17) Member of a party; (18) People met on travels self" and (17) "member of a party", which are related to "people", are included. The average percentage of posts concerning the items in group 3 was $28.7 \%$.

The items (12) "hot springs" (average posting percentage, $12.3 \%),(13)$ "sporting activities" (0.6\%), and (15) "unexpected events and mishaps" (7.4\%) were distributed far from the other items.

From the above findings, the percentage of posts was highest for items related to "visual attractions", which is a reasonable result considering that the results were collected from foreign tourists. However, the percentages of posts for items related to "tourist experiences during their trip" and "people" were also about $30 \%$. Thus, it was found that the contents of posts by foreign visitors to Japan can be classified into three groups.

\subsection{Trends of posts relative to different attributes}

Table 1 shows the number of respondents and the average number of types of posts for each region where foreign visitors are from, age group, and gender. In addition, the results of various tests of the difference in the average number are shown for each attribute. The numbers of types of posts of visitors were 7.18 for North America, 5.48 for Australia, 4.79 for Europe, 4.21 for Asia, and 4.00 for others, which showed a statistically significant difference with region of origin. The results of multiple comparisons indicate that the number of types of posts of visitors from North America was statistically significantly higher than those from Asia and Europe. The numbers of types of posts were 6.00 for visitors 15-19 years old, 4.94 for visitors 20-29 years old, and 5.46 for visitors 30-39 years old. The number of types of posts of visitors increased with decreasing age of the visitors, although these differences were not statistically significant. The number of types of posts of female visitors was 5.28 , higher than that of male visitors (4.66), although the difference was not statistically significant.

Table 2 shows the number of foreign visitors who wrote posts on SNSs related to the 18 items and the difference in the posting percentages based on gender. The posting percentages for 13 items were higher for female visitors. Only the posting percentage of the item related to "member of a party" showed a statistically significant difference between male and female visitors. For the five items for which the posting percentage of male visitors was higher, no statistically significant difference was found.

\subsection{Classifications in terms of the region where visitors are from}

Table 3 is a cross-tabulation in terms of region showing the number of visitors who wrote posts on SNSs related to the 18 items for each region where visitors were from. The percentages in each row of the table (horizontal percentages) add up to $100 \%$. A correspondence analysis was carried out using the horizontal percentages because the number of respondents from each region significantly varied, for example, the number of respondents from "other regions" was only 7. There were 
Table 1: Number of respondents and average number of types of posts for different attributes

\begin{tabular}{|c|c|c|c|c|c|c|c|c|}
\hline & & \multirow{2}{*}{$\begin{array}{l}\text { Number of } \\
\text { respondents }\end{array}$} & \multirow{2}{*}{ Average } & \multirow{2}{*}{$\begin{array}{l}\text { Standard } \\
\text { deviation }\end{array}$} & \multicolumn{4}{|c|}{ Test $^{1)}$} \\
\hline & & & & & $F$ value & $t$ value & $p$ value & Multiple comparison \\
\hline \multirow{5}{*}{ Region } & Asia & 47 & 4.21 & 2.62 & 3.855 & & 0.005 & Asia $<$ North America** \\
\hline & Europe & 66 & 4.79 & 2.83 & & & & Europe $<$ North America* \\
\hline & North America & 17 & 7.18 & 3.89 & & & & \\
\hline & Australia & 25 & 5.48 & 2.62 & & & & \\
\hline & Others & 7 & 4.00 & 2.16 & & & & \\
\hline \multirow{6}{*}{ Age } & $15-19$ & 10 & 6.00 & 3.20 & 1.354 & & 0.245 & \\
\hline & $20-29$ & 68 & 4.94 & 3.04 & & & & \\
\hline & $30-39$ & 46 & 5.46 & 3.25 & & & & \\
\hline & $40-49$ & 25 & 3.80 & 2.18 & & & & \\
\hline & $50-59$ & 11 & 4.55 & 1.92 & & & & \\
\hline & $60-69$ & 2 & 4.50 & 0.71 & & & & \\
\hline \multirow{2}{*}{ Gender } & Male & 87 & 4.66 & 2.78 & & -1.350 & 0.179 & \\
\hline & Female & 75 & 5.28 & 3.11 & & & & \\
\hline
\end{tabular}

Notes: ${ }^{1)}$ Independent $t$ test and $p$ value obtained by one-way analysis of variance; $* * p<0.01 ; * p<0.05$. Tukey method and honestly significant difference (HSD) method were used for multiple comparison.

many types of posts for which no visitors wrote posts, and there was only one post related to "sporting activities" among all the respondents. The analysis was carried out excluding these data as outliers (Figure 4).

The items located near the average score for Asia were "accommodations including hotels and Japanese inns", "hot springs", and "food and dining". Regarding "food and dining", the horizontal percentages for all regions exceeded $10 \%$. The horizontal percentage of "food and dining" for Asia was especially high at $18.2 \%$. The items located near the average score for Australia were "member of a party", "unexpected events and mishaps", and "animals and plants". The scores corresponding to Europe and North America were located near each other and close to the origin. This means that the visitors from Europe and North America wrote posts with similar contents and showed no unique characteristics compared with visitors from other regions. Note that there was no statistically significant difference in the horizontal percentages among age groups.

\section{Discussions}

Recently, tourism organizations in various countries and regions manage various types of SNSs to improve their tourism destination images [Kim et al., 2017]. To develop a strategy for attracting foreign visitors, the segmentation and selection of targets are important [Kotler et al., 2016]. It is effective to understand the difference in the contents of posts depending on individual differences (Sect. 4.3), gender (Sect. 4.4), and the region where visitors are from (Sect. 4.5) in attracting foreign visitors using SNSs [Yoo and Gretzel, 2011].

For example, to attract visitors from Asia, it is effective to ask influencers to relay their experience in enjoying their stay in Japanese inns at hot springs resorts and Japanese food. To attract female visitors, it is effective to introduce tourist spots where female visitors and their friends can take beautiful photos.

The percentage of posts on "animals and plants" by visitors from Australia is high. There are stations in Japan where various animals serve as stationmasters. It is effective to introduce the contact with animals unique to Japan, such as the route to meet the animal stationmaster while enjoying a trip on the local line. In addition, places where monkeys are immersed in hot springs and zoos where penguins march in the park may be effective.

It may also be effective for SNS accounts managed by the staff of tourist spots to publish both English and Japanese posts so that users can participate in writing comments because the contents of posts by visitors from North America are broad and they are generally willing to write posts on SNSs. As explained, the contents of posts by foreign visitors can be classified into three groups related to "visual attractions", "tourist experiences during their trip", and "people". Therefore, selecting themes on which users can make comments and structuring the contents of posts considering the three groups will be effective.

Hawkinson [2013] showed that there is a large mismatch in what SNS mediums Japanese business owners are using to promote their businesses online and what mediums are being used by potential international travellers in Japan. The suggestions obtained in this study should be implemented with understanding SNS mediums used by the target people.

\section{Conclusion}

In this study, a questionnaire survey was carried out target- 
Table 2: Number of respondents and average number of types of posts for different attributes

\begin{tabular}{|c|c|c|c|c|}
\hline & & Male & Female & $p$ value $^{1)}$ \\
\hline \multirow{3}{*}{ (1) Food and dining } & Those who wrote posts & 58 & 54 & 0.464 \\
\hline & Those who did not write posts & 29 & 21 & \\
\hline & Probability of posting & $66.7 \%$ & $72.0 \%$ & \\
\hline \multirow{3}{*}{ (2) Shops } & Those who wrote posts & 30 & 28 & 0.706 \\
\hline & Those who did not write posts & 57 & 47 & \\
\hline & Probability of posting & $34.5 \%$ & $37.3 \%$ & \\
\hline \multirow{3}{*}{ (3) Accommodations including hotels and Japanese inns } & Those who wrote posts & 16 & 19 & 0.284 \\
\hline & Those who did not write posts & 71 & 56 & \\
\hline & Probability of posting & $18.4 \%$ & $25.3 \%$ & \\
\hline \multirow{3}{*}{ (4) Famous tourist spots } & Those who wrote posts & 66 & 57 & 0.984 \\
\hline & Those who did not write posts & 21 & 18 & \\
\hline & Probability of posting & $75.9 \%$ & $76.0 \%$ & \\
\hline \multirow{3}{*}{ (5) Places or objects of interest other than famous tourist spots } & Those who wrote posts & 9 & 12 & 0.285 \\
\hline & Those who did not write posts & 78 & 63 & \\
\hline & Probability of posting & $10.3 \%$ & $16.0 \%$ & \\
\hline \multirow{3}{*}{ (6) Vehicles } & Those who wrote posts & 15 & 11 & 0.656 \\
\hline & Those who did not write posts & 72 & 64 & \\
\hline & Probability of posting & $17.2 \%$ & $14.7 \%$ & \\
\hline \multirow{3}{*}{ (7) Streetscapes } & Those who wrote posts & 24 & 26 & 0.331 \\
\hline & Those who did not write posts & 63 & 49 & \\
\hline & Probability of posting & $27.6 \%$ & $34.7 \%$ & \\
\hline \multirow{3}{*}{ (8) Specialties of Kanazawa City } & Those who wrote posts & 26 & 21 & 0.792 \\
\hline & Those who did not write posts & 61 & 54 & \\
\hline & Probability of posting & $29.9 \%$ & $28.0 \%$ & \\
\hline \multirow{3}{*}{ (9) Natural scenery } & Those who wrote posts & 40 & 41 & 0.270 \\
\hline & Those who did not write posts & 47 & 34 & \\
\hline & Probability of posting & $46.0 \%$ & $54.7 \%$ & \\
\hline \multirow{3}{*}{ (10) Animals and plants } & Those who wrote posts & 15 & 16 & 0.509 \\
\hline & Those who did not write posts & 72 & 59 & \\
\hline & Probability of posting & $17.2 \%$ & $21.3 \%$ & \\
\hline \multirow{3}{*}{ (11) Festivals and events } & Those who wrote posts & 6 & 8 & 0.394 \\
\hline & Those who did not write posts & 81 & 67 & \\
\hline & Probability of posting & $6.9 \%$ & $10.7 \%$ & \\
\hline \multirow{3}{*}{ (12) Hot springs } & Those who wrote posts & 12 & 8 & 0.546 \\
\hline & Those who did not write posts & 75 & 67 & \\
\hline & Probability of posting & $13.8 \%$ & $10.7 \%$ & \\
\hline \multirow{3}{*}{ (13) Sporting activities } & Those who wrote posts & 1 & 0 & 0.352 \\
\hline & Those who did not write posts & 86 & 75 & \\
\hline & Probability of posting & $1.1 \%$ & $0.0 \%$ & \\
\hline \multirow{3}{*}{ (14) Cultural experience at sites } & Those who wrote posts & 31 & 29 & 0.690 \\
\hline & Those who did not write posts & 56 & 46 & \\
\hline & Probability of posting & $35.6 \%$ & $38.7 \%$ & \\
\hline \multirow{3}{*}{ (15) Unexpected events and mishaps } & Those who wrote posts & 6 & 6 & 0.789 \\
\hline & Those who did not write posts & 81 & 69 & \\
\hline & Probability of posting & $6.9 \%$ & $8.0 \%$ & \\
\hline \multirow{3}{*}{ (16) Myself } & Those who wrote posts & 23 & 29 & 0.096 \\
\hline & Those who did not write posts & 64 & 46 & \\
\hline & Probability of posting & $26.4 \%$ & $38.7 \%$ & \\
\hline \multirow{3}{*}{ (17) Member of a party } & Those who wrote posts & 16 & 25 & $0.029 *$ \\
\hline & Those who did not write posts & 71 & 50 & \\
\hline & Probability of posting & $18.4 \%$ & $33.3 \%$ & \\
\hline \multirow{3}{*}{ (18) People met on travels } & Those who wrote posts & 11 & 6 & 0.336 \\
\hline & Those who did not write posts & 76 & 69 & \\
\hline & Probability of posting & $12.6 \%$ & $8.0 \%$ & \\
\hline
\end{tabular}

Notes: ${ }^{1)} p$ value obtained by chi-square test; $* p<0.05$. 
Table 3: Cross-tabulation table in terms of region

\begin{tabular}{|c|c|c|c|c|c|c|c|c|c|}
\hline & (1) & (2) & (3) & (4) & (5) & (6) & (7) & (8) & (9) \\
\hline \multirow{2}{*}{ Asia } & 36 & 17 & 13 & 29 & 2 & 5 & 8 & 16 & 19 \\
\hline & $18.2 \%$ & $8.6 \%$ & $6.6 \%$ & $14.6 \%$ & $1.0 \%$ & $2.5 \%$ & $4.0 \%$ & $8.1 \%$ & $9.6 \%$ \\
\hline \multirow{2}{*}{ Europe } & 40 & 20 & 12 & 53 & 9 & 12 & 23 & 18 & 31 \\
\hline & $12.7 \%$ & $6.3 \%$ & $3.8 \%$ & $16.8 \%$ & $2.8 \%$ & $3.8 \%$ & $7.3 \%$ & $5.7 \%$ & $9.8 \%$ \\
\hline \multirow{2}{*}{ North America } & 16 & 8 & 4 & 15 & 5 & 5 & 6 & 10 & 13 \\
\hline & $13.1 \%$ & $6.6 \%$ & $3.3 \%$ & $12.3 \%$ & $4.1 \%$ & $4.1 \%$ & $4.9 \%$ & $8.2 \%$ & $10.7 \%$ \\
\hline \multirow{2}{*}{ Australia } & 16 & 11 & 5 & 19 & 4 & 4 & 10 & 2 & 14 \\
\hline & $11.7 \%$ & $8.0 \%$ & $3.6 \%$ & $13.9 \%$ & $2.9 \%$ & $2.9 \%$ & $7.3 \%$ & $1.5 \%$ & $10.2 \%$ \\
\hline \multirow{3}{*}{ Others } & 4 & 2 & 1 & 7 & 1 & 0 & 3 & 1 & 4 \\
\hline & $14.3 \%$ & $7.1 \%$ & $3.6 \%$ & $25.0 \%$ & $3.6 \%$ & $0.0 \%$ & $10.7 \%$ & $3.6 \%$ & $14.3 \%$ \\
\hline & (10) & (11) & (12) & (13) & (14) & (15) & (16) & (17) & (18) \\
\hline \multirow{2}{*}{ Asia } & 4 & 2 & 9 & 0 & 15 & 2 & 10 & 9 & 2 \\
\hline & $2.0 \%$ & $1.0 \%$ & $4.5 \%$ & $0.0 \%$ & $7.6 \%$ & $1.0 \%$ & $5.1 \%$ & $4.5 \%$ & $1.0 \%$ \\
\hline \multirow{2}{*}{ Europe } & 13 & 7 & 7 & 0 & 27 & 3 & 21 & 12 & 8 \\
\hline & $4.1 \%$ & $2.2 \%$ & $2.2 \%$ & $0.0 \%$ & $8.5 \%$ & $0.9 \%$ & $6.6 \%$ & $3.8 \%$ & $2.5 \%$ \\
\hline \multirow{2}{*}{ North America } & 5 & 3 & 2 & 0 & 9 & 2 & 8 & 7 & 4 \\
\hline & $4.1 \%$ & $2.5 \%$ & $1.6 \%$ & $0.0 \%$ & $7.4 \%$ & $1.6 \%$ & $6.6 \%$ & $5.7 \%$ & $3.3 \%$ \\
\hline \multirow{2}{*}{ Australia } & 8 & 2 & 1 & 1 & 8 & 5 & 11 & 13 & 3 \\
\hline & $5.8 \%$ & $1.5 \%$ & $0.7 \%$ & $0.7 \%$ & $5.8 \%$ & $3.6 \%$ & $8.0 \%$ & $9.5 \%$ & $2.2 \%$ \\
\hline \multirow{2}{*}{ Others } & 1 & 0 & 1 & 0 & 1 & 0 & 2 & 0 & 0 \\
\hline & $3.6 \%$ & $0.0 \%$ & $3.6 \%$ & $0.0 \%$ & $3.6 \%$ & $0.0 \%$ & $7.1 \%$ & $0.0 \%$ & $0.0 \%$ \\
\hline
\end{tabular}

Notes: (1) Food and dining; (2) Shops; (3) Accommodations including hotels and Japanese inns; (4) Famous tourist spots; (5) Places or objects of interest other than famous tourist spots; (6) Vehicles; (7) Streetscapes; (8) Specialties of Kanazawa City; (9) Natural scenery; (10) Animals and plants; (11) Festivals and events; (12) Hot springs; (13) Sporting activities; (14) Cultural experience at sites; (15) Unexpected events and mishaps; (16) Myself; (17) Member of a party; (18) People met on travels

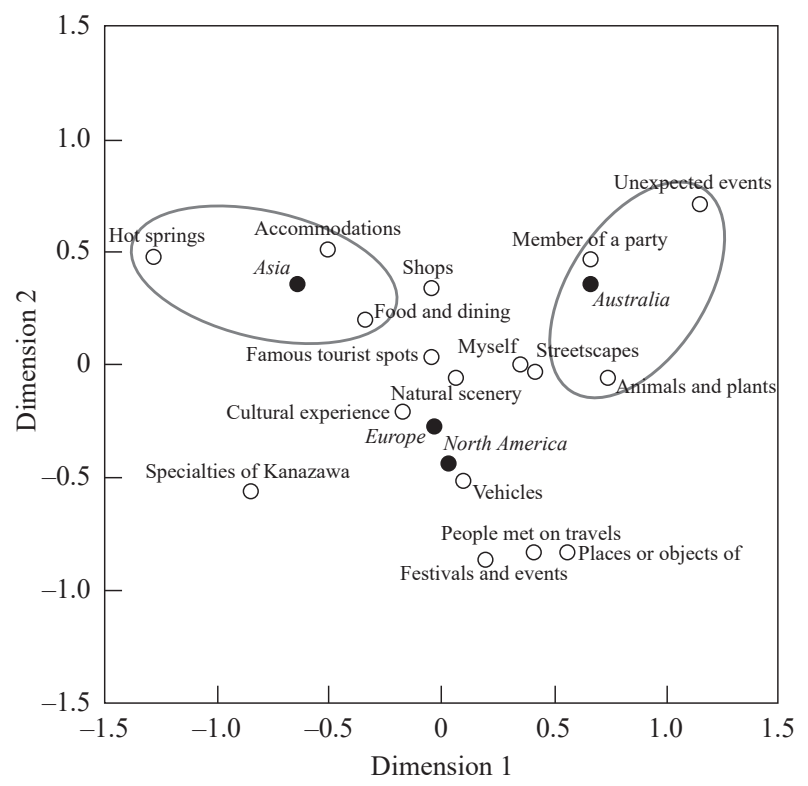

Figure 4: Classification of contents of posts for different regions where visitors are from ing foreign visitors who visited Kanazawa City in Ishikawa prefecture and wrote posts on SNSs regarding their trip. The following five findings were obtained.

- The results indicate that the posts by foreign visitors had a wider range of contents than those by Japanese tourists. The sum of the percentages of posts on 19 items for foreign visitors was $496.7 \%$ (multiple answers allowed), compared with $219.4 \%$ for Japanese tourists.

- The contents of posts by foreign visitors were classified into three groups: "visual attractions", "tourist experiences during their trip", and "people".

- Compared with visitors from Asia and Europe, the number of types of posts by visitors from North America tended to be high.

- The percentages of posts on "accommodations including hotels and Japanese inns", "hot springs", and "food and dining" were higher among visitors from Asia than those from other regions. The percentages of posts on "member of a party", "unexpected events and mishaps", and "animals and plants" were higher among visitors from Australia than those from other regions. The visitors from Europe and North America wrote posts with similar contents and showed no unique 
characteristics compared with other visitors.

- The number of posts on "member of a party" tended to be higher for female visitors than for male visitors.

To develop a strategy for attracting foreign visitors using SNSs, understanding trends in terms of their attributes, writing effective posts, and encouraging visitors to write posts are important [Sawada and Yoshida, 2017]. In future studies, it is necessary to examine the texts of posts by foreign visitors on SNSs and the trends of posts in terms of different attributes in more detail. The analysis the trends of posts by country is also necessary because there are various countries in Asia and Europe.

\section{Acknowledgements}

This study was supported by JSPS KAKENHI Grant Number 19K12600. I would like to thank Mr. Michio Shibano for cooperating with the questionnaire survey.

\section{References}

Burgess, S., Sellitto, C., Cox, C., and Buultjens, J. (2011). Trust perceptions of online travel information by different content creators: Some social and legal implications. Information Systems Frontiers, Vol. 13, No. 2, 221-235.

Fotis, J., Buhalis, D., and Rossides, N. (2011). Social media impact on holiday travel: The case of the Russian and the FSU markets. International Journal of Online Marketing, Vol. 1, No. 4, 1-19. doi:10.4018/ijom.2011100101.

Hawkinson, E. (2013). Social media for international inbound tourism in Japan: A research model for finding effective eWOM mediums. JAFIT International Tourism Review, Vol. 20, 41-48.

Hu, Y., Manikonda, L., and Kambhampati, S. (2014). What we Instagram: A first analysis if Instagram photo content and user types. Proceedings of the Eighth International AAAI Conference on Weblogs and Media, 595-598.

Hu, F. H. and Wei, G. (2013). The impact of the knowledge sharing in social media on consumer behaviour. Proceedings of the Thirteenth International Conference on Electronic Business, 71-85.

Icoz, O., Kutuk, A., and Icoz, O. (2018). Social media and consumer buying decisions in tourism: The case of Turkey. PASOS. Journal of Tourism and Cultural Heritage, Vol. 16, No. 4, 1051-1066. doi.org/10.25145/j.pasos.2018.16.073.

Japan Travel and Tourism Association (2017). 2016 states and trends of tourism: 35 th survey into the actual state of citizen tourism. (in Japanese)

Kanazawa City (2018). 2017 survey results report on Kanazawa City tourism (Retrieved February 3, 2019 from https:// www4.city.kanazawa.lg.jp/data/open/cnt/3/14897/1/kankouchosa2017.pdf. (in Japanese)

Kim, S.-E., Lee, K. Y., and Shin, S. (2017). Effects of tourism information quality in social media on destination image formation: The case of Sina Weibo. Information \& Manage- ment, Vol. 54, No. 6, 687-702. doi:10.1016/j.im.2017.02.009.

Kotler, P., Bowen, J. T., Makens, J., and Baloglu, S. (2016). Marketing for hospitality and tourism, 7th edition, Pearson.

Ministry of Internal Affairs and Communications (2018). White paper on information and communications in Japan. (in Japanese)

Ministry of Land, Infrastructure, Transport and Tourism (2018). 2017 foreign visitors consumption trends survey report. (in Japanese)

Sawada, A. and Yoshida, T. (2017). Increasing the attractiveness of tourism-related Facebook pages based on emotion analysis of user comments. Journal of Global Tourism Research, Vol. 2, No. 2, 105-114.

Uchida, O. (2006). Correspondence analysis of questionnaire responses by SPSS. TokyoTosho. (in Japanese)

Yoo, K. H. and Gretzel, U. (2011). Influence of personality on travel-related consumer-generated media creation. Computers in Human Behavior, Vol. 27, No. 2, 609-621. doi:10.1016/ j.chb.2010.05.002.

Zivkovic, R., Gajic, J., and Brdar, I. (2014). The impact of social media on tourism. Singidunum Journal of Applied Sciences Supplement, 758-761. doi.org/10.15308/sinteza-2014-758-761.

(Received September 25, 2021; accepted October 18, 2021) 